\title{
Una aproximación a las acciones colectivas de los docentes santafesinos frente a las políticas educativas (1983-1989). EI caso de la Asociación de Magisterio de Santa Fe *
}

\author{
Carlos Marcelo Andelique y María Cecilia Tonon ${ }^{* *}$
}

\section{Resumen}

El primer gobierno posdictadura y las asociaciones gremiales docentes configuraron agendas políticas y gremiales, respectivamente, que estaban fuertemente condicionadas por el retorno a la democracia y las expectativas que se habían gestado en torno a ello. Estos condicionantes históricos sin duda operaron en las decisiones y acciones que emprendieron los docentes tanto en la provincia de Santa Fe como a nivel nacional.

En este trabajo nos interesa analizar las características que asumieron las acciones colectivas llevadas a cabo por los docentes santafesinos nucleados en la Asociación de Magisterio de Santa Fe entre 1983 y 1989, y conjeturar sobre las posibles causas que explican estos procesos de conflictividad que se manifestaron en el período histórico objeto de este trabajo.

Palabras clave: acciones colectivas-sindicalismo docente santafesino-políticas educativas (1983-1989).

\footnotetext{
* Artículo recibido el 29 de febrero de 2016. Aceptado el 8 de agosto de 2016.

** Centro de Estudios Sociales Interdisciplinarios del Litoral (CESIL) - Facultad de Humanidades y Ciencias de la Universidad Nacional del Litoral (Santa Fe, Argentina). marceloandelique@yahoo.com.ar; tononcec@gmail.com
} 


\section{Abstract}

The first posdictatorship government and the teachers' trade unions set political and unionist agendas that were strongly conditioned by the return to democracy and the expectations generated by such development. These historical factors undoubtedly influenced the decisions and actions undertaken by teachers both in the province of Santa Fe and at national level.

In this paper, we aim to detect the collective actions carried out by teachers from AMSAFE between 1983 and 1989 and to infer the possible reasons behind conflictive processes occurring in the historical period under study.

Keywords: collective actions-teacher union from Santa Fe-education policies (1983-1989).

\section{Introducción}

En las últimas dos décadas del siglo $X X$ se dio una transformación del papel del Estado en las relaciones entre capital y trabajo. De una presencia fundamental como árbitro de esas relaciones, se pasó a una capacidad de regulación escasa o nula, en el marco de cambios en la naturaleza y formas de trabajo (Fernández, 2005: 11-44). En Argentina, esta situación se hizo evidente en los ochenta con el comienzo de la implementación de medidas de reforma durante el alfonsinismo, que puso en tensión los objetivos democratizadores del gobierno, con una política económica que fue sembrando las condiciones para la acumulación privada, el fortalecimiento de la competitividad internacional y la liberación económica -ya implementada desde mediados de los setenta, y con distinto éxito, por los regímenes dictatoriales del Cono Sur (Torre, 1998)-.

De esta forma, si en un principio la política económica alfonsinista intentó paliar la difícil herencia económica del período militar, priorizando la situación de los trabajadores, impulsando el mercado interno y favoreciendo la recuperación de la economía en general, esto dio un vuelco considerable a mediados de los ochenta.

Para ese entonces, el gobierno tuvo que enfrentarse con dos problemas cada vez más crecientes: la inflación y el déficit fiscal. En este contexto, poco a poco el gobierno alfonsinista fue mutando sus propósitos originarios en torno a la política económica, reorientando sus relaciones con aquellos actores que habían surgido al calor de la 
dictadura militar -como los Capitanes de la Industria-, acciones que trastocaron las vinculaciones con otros grupos sociopolíticos, y que sentaron "las bases para que el ajuste de la economía recayera sobre los sectores populares y las fracciones más débiles de la burguesía..." (Ortiz y Schorr, 2006: 293).

Esto marcó una impronta particular del alfonsinismo en las relaciones con el sindicalismo, especialmente con aquellos gremios en los que el Estado era el empleador. Sucedió que al calor de las transformaciones que ocurrieron en la matriz estatal y en el mercado laboral desde mediados de los años cincuenta, los empleados del Estado, entre estos, los docentes, manifestaron una disminución de los beneficios salariales y del status general de la profesión. Estas circunstancias colaboraron para que estos grupos modificaran sus pautas identitarias, emparejándose cada vez más con el resto de los trabajadores (Diana Menéndez, 2005; Orlansky, 1996; Novaro, 2009).

El gobierno de Alfonsín se encontró, de esta manera, ante un gremio docente heterogéneo, fluctuante y capaz de reorganizarse en función de cómo se plantearan las circunstancias. Entonces, ¿cuál fue la situación gremial de los docentes en los ochenta?, ¿qué problemáticas atravesaron?, ¿cuáles fueron sus relaciones con el Estado nacional?, ¿qué acciones colectivas llevaron a cabo los docentes en la provincia de Santa Fe frente a las políticas educativas?, son algunos de los interrogantes que intentamos desentrañar en este trabajo, particularmente desde un estudio de caso. Nos interesa analizar las características que asumieron los conflictos en dicho período, las diferentes causas que movilizaron a los docentes nucleados en la Asociación del Magisterio de Santa Fe (AMSAFE) ${ }^{1}$, los canales de negociación utilizados, las principales reivindicaciones y reclamos que se plantearon ${ }^{2}$.

\section{Los ochenta: situación educativa y poder sindical}

En la década de los ochenta, la Confederación de Trabajadores de la Educación de la República Argentina (CTERA) ${ }^{3}$, que nucleó a la mayor parte de los docentes desde su

\footnotetext{
${ }^{1}$ De aquí en adelante AMSAFE

2 Por razones de espacio no podemos detenernos a plantear los antecedentes y encuadres teóricoreferenciales de nuestro trabajo, como tampoco un tratamiento de las fuentes analizadas. A modo de breve presentación, mencionaremos como antecedentes fundamentales para el análisis de la situación docente en los ochenta a los textos de Braslavsky (1989 y 1995), Glaz (2002), Migliavacca (2006), Andelique y Tonon (2014). El soporte teórico-referencial se complementa con textos de carácter general que nos permiten contextualizar el objeto de estudio, como son las contribuciones de Novaro y Palermo (2006), Novaro (2009), Cavarozzi (2006), Fernández (2005), Schneider (2000) y Pozzi (1988), la compilación de Pucciarelli (2006) y Alonso (2006), entre otros, y el aporte del texto de Tilly (2000) para encuadrar el estudio en el análisis de la acción colectiva. Las fuentes primarias principales son básicamente documentos escritos, como diarios -de alcance provincial-, leyes y materiales del gremio docente santafesino -actas de asambleas, cartas, notificaciones, etc-. Hemos realizado varias entrevistas a diferentes representantes gremiales, de las que hemos referido solo algunas en este artículo. Nos ha quedado una deuda pendiente con el tratamiento de fuentes relativas al gobierno provincial, que intentaremos saldar en un próximo trabajo.

${ }^{3}$ De aquí en adelante CTERA.
} 
formación en 1973, se encontraba en un proceso interno de redefinición de liderazgos que puso en jaque la coherencia interna y la representatividad del gremio a nivel nacional. Producto de estas diferencias se evidenciaron dos líneas bien definidas al interior de la dirigencia sindical docente. Por un lado, la facción liderada por el dirigente de Río Negro, Wenceslao Arizcuren -la CTERA " $\mathrm{A}^{-}{ }^{4}$, en la que se alineaban sectores de izquierda -comunistas, trotskistas y socialistas- y algunos grupos provenientes del radicalismo; por otro lado, la lista "Celeste" -o CTERA "G"-5 coordinada por el dirigente de la provincia de Mendoza, Marcos Garcetti, que reunió tras de sí a sectores de filiación mayormente peronista y que, más tarde, fue reconocida oficialmente por el Ministerio de Trabajo de la Nación. Esta división se dio el 17 de julio de 1987, en el marco del V Congreso Ordinario de la CTERA realizado en la ciudad de Santa Fe.

Esta polarización repercutió de diferentes maneras en las entidades jurisdiccionales adheridas a esta confederación. En el caso de la AMSAFE ${ }^{6}$, la mayoría de sus dirigentes se alineó con el sector de Arizcuren, dado que en un contexto de múltiples líneas políticas -radicales, comunistas, trotskistas, etc.- que actuaban en el seno del gremio durante esta década se optó en un comienzo por el sector de la CTERA más pluralista y democrático, menos vinculado a los líderes sindicales peronistas de la Confederación General del Trabajo ${ }^{7}$, de carácter más burocrático. No obstante, la falta de reconocimiento legal por el Ministerio de Trabajo de la CTERA liderada por Arizcuren fue debilitando esta opción y la AMSAFE, en el marco de una fuerte discusión interna, decidió volver a la CTERA "legal" dirigida por Garcetti el 8 de abril de $1988^{8}$.

A estas disputas gremiales internas -provinciales y nacionales- hay que sumarle las difíciles circunstancias socioeconómicas que impactaron negativamente en la situación laboral y en los salarios de los trabajadores en general (Ortiz y Schorr, 2006: 326-328), y de los docentes en particular'.

Otro de los aspectos íntimamente vinculado con los procesos referidos anteriormente fue la situación del sistema educativo argentino. En este sentido, se puede señalar que, con la renovación democrática, también se alentó la transformación educativa, idea que

\footnotetext{
${ }^{4}$ De aquí en adelante CTERA "A".

${ }^{5}$ De aquí en adelante CTERA " $G$ ".

${ }^{6}$ En este gremio se evidenció una fuerte presencia de simpatizantes y militantes del radicalismo, además de la participación secundaria de sectores de izquierda y una creciente intervención de grupos peronistas. Estas tendencias variaron según los diferentes departamentos.

${ }^{7}$ De aquí en adelante CGT.

${ }^{8}$ Diario El Litoral, 09/04/88, p. 4.

${ }^{9}$ Como nos señalara una docente y activa gremialista de aquel momento: "La situación del docente era pésima (...) no ganábamos nada... nadie quería ser maestro. Se recibían y la gente no quería ser maestro. Después [de los militares] (...) ya vino otra vez la crisis, porque con Alfonsín no nos pudimos poner de acuerdo (...) Fue la gran apertura, todo el mundo protestaba, pedía aumento, pedía aumento y a nosotros no nos daban. Era el momento de actuar". Entrevista a Docente 1 [grabación], realizada por María Cecilia Tonon en Rafaela el 21/03/2013. Registro en formato MP3. Archivo personal de los autores de este trabajo.
} 
estuvo presente en todos los partidos políticos. En el caso del partido oficialista, el radicalismo llevó adelante una política que apuntó a abrir el debate a los diferentes actores sociales que intervenían en el proceso educativo. Para ello, se sancionó una ley que dio origen al Congreso Pedagógico Nacional (Ministerio de Educación, 1984).

En los debates que se llevaron a cabo en el congreso, se transparentaron la crisis y las principales falencias del sistema educativo en su conjunto respecto de distintos tópicos: la formación, capacitación y actualización de los docentes, los salarios, las condiciones edilicias, el equipamiento, los contenidos del currículum -enciclopedista, anticuado-, etc. Sin embargo, frente al diagnóstico, el gobierno nacional no tuvo respuestas concretas, ni en proyectos, ni en los hechos. De esta forma, se generó una profunda contradicción entre los discursos de democratización institucional del sistema educativo y las políticas concretas que el gobierno llevó a cabo. De hecho, tal como plantea Migliavacca (2006), los alcances del congreso como de la política educativa del radicalismo en general se vieron restringidos en tanto el gobierno tomó medidas que aseguraron la continuidad de políticas neoliberales impulsadas desde la última dictadura militar.

A lo largo de la década de los ochenta se pueden reconocer importantes acciones colectivas llevadas a cabo por diferentes sindicatos docentes, pero es hacia finales de la década cuando estas adquieren un alto nivel de organización y movilización nacional, que se intensificaron por la creciente inflación que habían gestado las políticas económicas fallidas -Plan Austral y Primavera-, por la paulatina deslegitimación del gobierno que tuvo su expresión más rotunda en la derrota electoral de 1987 con el consecuente fortalecimiento del peronismo. En este marco, se intensificó la conflictividad social y en el caso específico de los docentes, la diferenciación salarial se constituyó en el elemento aglutinador que los movilizó a nivel nacional. Al respecto, Glaz plantea que las diferencias en los sueldos se debían a que eran los gobiernos de cada una de las provincias las que se hacían cargo de pagarlos. De esta manera, las provincias con mayores recursos, como Córdoba o Buenos Aires, tenían ingresos suficientes como para sumar al básico un extra. Pero a pesar de estos beneficios, "la docencia estaba mal paga. Si esta era la situación de las jurisdicciones con mayores recursos, imaginemos en qué estado se encontraba el salario en las otras provincias" (Glaz, 2013: 21).

\section{El sindicalismo docente santafesino ante las políticas educativas}

\section{Entre el diálogo y los conflictos aislados (1983-1987)}

A comienzos del ochenta, el sindicalismo docente en la provincia de Santa Fe enfrentó la compleja situación de reorganizarse tras el período militar. Las principales entidades gremiales que nuclearon a los docentes de la provincia fueron la AMSAFE, el Sindicato Argentino de Docentes Particulares (SADOP), la Unión Docentes Argentinos (UDA), la 
Asociación de Educadores Particulares (AEP) y la Asociación de Maestros de Enseñanza Técnica (AMET), que respondían a los vaivenes de la política gremial nacional que lideraban las entidades nacionales como la CTERA, la UDA, la Federación de Agrupaciones Gremiales de Educadores (FAGE) que, además, entraban en la discusión de las internas de la CGT (Novaro, 2009: 81).

Meses antes de las elecciones de octubre de 1983 se dio un ciclo de protesta muy importante que abarcó a diferentes sindicatos de alcance nacional, entre los que se encontraban los sindicatos docentes ${ }^{10}$. En la provincia de Santa Fe, la AMSAFE y otras organizaciones gremiales de alcance nacional venían sosteniendo una serie de reclamos centrada especialmente en la recomposición salarial. Sin embargo, esta reivindicación no fue la única. Tres reclamos aparecieron como nodales para los docentes: el incremento en las remuneraciones, la unificación salarial para todos los docentes del país y la reincorporación de los docentes cesanteados desde 1976.

Hacia fines de 1982, las organizaciones sindicales docentes se mostraron fortalecidas frente a un gobierno dictatorial ${ }^{11}$ totalmente desprestigiado luego de la Guerra de Malvinas, en un contexto de desgaste general del régimen y en un proceso de politización ${ }^{12}$ que se profundizaba en el marco de las cercanas elecciones que renovarían todos los cargos de los diferentes niveles del Estado. Esta situación no fue privativa del sindicalismo docente ni de la provincia de Santa $\mathrm{Fe}$, ya que asistimos a nivel nacional a una serie de medidas de acción contra el gobierno, especialmente de los sindicatos estatales. Fue como si una gran compuerta se hubiese abierto luego de varios años en que las movilizaciones de los trabajadores habían sido prohibidas.

Sin embargo, las medidas de protesta fueron imputadas por sectores del gobierno y algunos partidos políticos como desestabilizadoras sociales. En este marco, muchas direcciones sindicales, especialmente las lideradas por sectores peronistas, asumieron posiciones conciliadoras frente al gobierno. En definitiva, las burocracias sindicales trataron de mantener la protesta en el marco de canales de expresión institucionales que no terminaran en procesos de acciones colectivas incontrolables. En cierta medida, había una especie de acuerdo tácito por llegar a las elecciones nacionales en un marco

\footnotetext{
${ }^{10}$ Para profundizar el análisis de la conflictividad obrera hacia fines de la dictadura iniciada en 1976, véase: Schneider, A. (2000). 'Ladran Sancho...'. Dictadura y clase obrera en la zona norte del Gran Buenos Aires, en Camarero, H.; Pozzi, P. y Schneider, A., De la revolución libertadora al menemismo. Historia social y política argentina. Buenos Aires: Imago Mundi. Para un análisis más general, véase Novaro, M. y Palermo, V. (2006). La dictadura militar 1976/1983. Del golpe de Estado a la restauración democrática, Buenos Aires, Paidós.

${ }^{11}$ En Santa Fe, la autoridad máxima era el doctor Héctor C. Salvi, gobernador, y en el Ministerio de Educación y Cultura de la provincia, el profesor Carlos Marí Rousseau, que respondía a la cartera nacional de Educación del ministro Cayetano Licciardo.

${ }^{12}$ Los conflictos docentes contaban con un importante aval por parte de la población, diario El Litoral, 07/09/83, p. 9. De la misma manera, muchas organizaciones políticas, gremiales y culturales aparecen juntas expidiéndose a favor de los docentes, cuando en otro contexto hubieran estado, posiblemente, divididas y enfrentadas, diario El Litoral, 10/09/83, p. 9.
} 
de paz social ${ }^{13}$. No obstante, esto no impidió la aparición de movilizaciones y huelgas de algunos sindicatos ya que, como bien señala Pozzi (1988: 135), se desarrolló una "dialéctica en torno a las medidas de fuerza desde la base que lleva[ron] a la burocracia a tratar de frenarlas, pero que en ese intento [debió] asumirlas e impulsarlas para impedir que se descontrolen".

En el marco de esta lógica planteada por Pozzi, se pueden comprender y analizar las acciones colectivas de docentes y estatales que se desarrollaron en los meses previos a las elecciones de octubre de 1983, donde las demandas salariales de trabajadores estatales y docentes se profundizaron y generaron una serie de huelgas importante. En la provincia de Santa Fe, la AMSAFE venía realizando algunas medidas de protesta desde antes del receso de invierno que se profundizaron entre agosto y septiembre. Durante este último mes, la lucha de los docentes santafesinos coincidió en algunas jornadas con huelgas convocadas a nivel nacional por la CTERA y UDA. Entre los reclamos, además del aumento salarial, se pedía la aplicación de las bonificaciones de antigüedad establecidas en el Estatuto Docente, la reincorporación de los docentes declarados cesantes y prescindibles desde 1976 sin sumario previo, entre otras reivindicaciones previsionales y laborales ${ }^{14}$. Además de las huelgas, se organizaron movilizaciones para exteriorizar el descontento ${ }^{15}$, que contó con la solidaridad de partidos políticos y asociaciones civiles, lo cual daba cuenta del importante grado de movilización social que atravesaba a la sociedad. Pero la situación pudo ser canalizada a través de vías institucionales. Efectivamente, dirigentes de ambas CGT regionales alineadas a las CGT-Brasil y CGT-Azopardo- y representantes de los gremios docentes firmaron un acta acuerdo ${ }^{16}$, solucionando y cerrando un conflicto que se había dilatado demasiado en el tiempo, a pocos días de celebrarse las elecciones.

La renovación democrática generó nuevas expectativas en la docencia santafesina y abrió un proceso de reorganización interna ${ }^{17}$ en la AMSAFE para obtener la personería

\footnotetext{
${ }^{13}$ Un ejemplo de ello es el comunicado de la Unión del Personal Civil de la Nación (UPCN), Seccional Santa Fe, donde se propone la aceptación de los incrementos salariales, cfr. diario El Litoral, 14/09/83, p. 10. Otro ejemplo es la actitud que asumió la CGT-Brasil a nivel nacional. En una entrevista ante la posibilidad de un acuerdo, su dirigente, Saúl Ubaldini, aclaraba que no había hecho ningún acuerdo ni concertación con el gobierno militar saliente. Sin embargo, aunque reconocía que las medidas socioeconómicas de emergencia no eran satisfactorias, planteaba que tenían una prioridad "...legar a la democracia". De esta manera, se justificaba la actitud conciliadora y expectante de los dirigentes sindicales, cfr. diario El Litoral, 02/09/83, p. 5.

${ }^{14}$ Diario El Litoral, 20/09/83, p. 7.

${ }^{15}$ La protesta expresaba también las críticas y el descrédito en el cual se había sumido el régimen. En uno de los cánticos que se reproducían en la prensa local se decía: "Conteste, conteste sin temor. Cuánto gana un maestro, cuánto gana un militar", diario El Litoral, 22/09/83, p. 4.

${ }^{16}$ Diario El Litoral, 28/09/83, p. 8.

${ }^{17}$ Fue un proceso de refundación sindical posdictadura que recuperaba en parte la tradición de lucha de lo que fueran la Federación Provincial del Magisterio, las asociaciones que funcionaban en diferentes departamentos provinciales y el FUSTE. Aunque se puede rastrear cierta continuidad en los militantes y docentes afiliados, institucionalmente la AMSAFE se configuró como un sindicato único, cuya lógica de
} 
gremial, elemento fundamental que legitima y regula las relaciones con la patronal. No obstante, la falta de este reconocimiento jurídico no impidió la realización de acciones contenciosas $^{18}$. Como recuerda una docente: "vos no sabés... nosotros no teníamos personería gremial, hacíamos un paro y teníamos que ir acompañadas por un dirigente sindical del sindicato que encontráramos a hablar con el gobernador o con el Ministro" ${ }^{19}$. Producto de la obtención de la personería gremial fueron convocadas el 2 de septiembre de 1984 las elecciones generales. De allí surgió la primera Comisión Directiva del período democrático, cuyo secretario fue César Oxley.

Las primeras acciones entre el gremio y el primer gobierno democrático de la provincia apostaron al diálogo. En el Ministerio de Educación de la provincia ${ }^{20}$ se dio una política tendiente a la construcción de consensos, creando comisiones de trabajo ${ }^{21}$ integradas por representantes de los principales sindicatos docentes y del gobierno. Esto marcó un fuerte contraste respecto de la situación anterior. En un proceso de democratización general, las estructuras del Estado abrieron canales de comunicación para que los docentes pudieran plantear demandas y realizar propuestas a través de sus representantes gremiales.

En el sindicato se formaron subcomisiones que apuntaron a generar propuestas de acción y reformas de cada uno de los niveles docentes para elevar al gobierno. Por ejemplo, se formaron la subcomisión de la Escuela de Enseñanza Media para Adultos (EEMPA) y de nivel medio -que habían sido los sectores más relegados en el sistema educativo provincial-, de maestros especiales, entre otros.

En general, entre 1984 y 1986, las relaciones entre los sindicatos docentes y el gobierno provincial se desenvolvieron de manera negociada, recurriendo a la discusión en comisiones formadas a los efectos de problemáticas particulares que preocupaban a la docencia santafesina. Esto no significó negar la existencia de conflictos que, de hecho, los hubo ${ }^{22}$, pero en ningún momento adquirieron grandes dimensiones como

\footnotetext{
funcionamiento interno era muy distinta de los agrupamientos sindicales anteriores, siguiendo los lineamientos y principios fundacionales de la CTERA creada en 1973.

${ }^{18}$ Ejemplo de esto fueron las huelgas y movilizaciones llevadas a cabo durante las décadas del '60 y '70. Véase al respecto Andelique (2012), Andelique y Tonon (2014), Andelique y Tonon (2016).

${ }^{19}$ Entrevista a Docente 1 [grabación], realizada por María Cecilia Tonon en Rafaela el 21/03/2013. Registro en formato MP3. Archivo personal de los autores de este trabajo.

20 Tras las elecciones de 1983, el gobierno provincial estuvo bajo el poder de sectores del peronismo con las gobernaciones de José María Vernet (1983-1987) y Víctor Félix Reviglio (1987-1991). Para ampliar su análisis, véase Alonso, L. (2006). Los Ministros de Educación actuantes en cada una de las administraciones fueron: Domingo Colasurdo (1983-1985), Eduardo Cevallo, el Dr. Juan Carlos Gómez Barinaga (1985-1987), Jorge Fernández (1987-1989) y Héctor García Solá (1989-1991).

${ }^{20}$ Diario El Litoral, 4/03/1988, p. 1.

${ }^{21}$ Las mesas de trabajo que se fijaron trataron los siguientes temas: política salarial, asistencialidad al alumno, aspectos técnicos-pedagógicos y legislativos y normativos, diario El Litoral, 17/02/1984, p. 5.

22 Sobre todo en los niveles medio y universitario, que participan a través de la CTERA y de la CONADU, respectivamente, diario El Litoral, 28/02/1985, 2/03/1985 y 5/03/1985.
} 
fueron los de 1983 o las grandes huelgas que se produjeron en la segunda mitad de la década, especialmente a partir de 1986.

Esto coincide con las oscilaciones en las relaciones entre sindicalismo y oficialismo a nivel nacional, en las que las circunstancias de las políticas económicas implementadas por el gobierno de Alfonsín y la situación salarial de la mayoría de los trabajadores fueron regulando y marcando las instancias de conflicto. Sin adentrarnos en la profundización de estas cuestiones, cabe mencionar la recurrencia de procesos inflacionarios, el impacto del Plan Austral y las huelgas generales llevadas a cabo por la CGT de Ubaldini en este período (Cavarozzi, 2006).

En este marco, no debemos dejar de tener en cuenta que todos los sindicatos respondieron a políticas de las confederaciones nacionales. En el caso específico de la AMSAFE, muchas de las acciones colectivas llevadas a cabo -movilizaciones, huelgas aisladas- reflejaron las decisiones que desde el confederal de la CTERA se tomaban ante políticas del gobierno nacional ${ }^{23}$. Pero también expresaron problemas puntuales propios de la administración provincial que habían generado permanentes descontentos entre los docentes santafesinos. Los principales motivos que los movilizaron fueron los siguientes: atrasos en la efectivización de los salarios, deudas pendientes con interinos y reemplazantes, omisiones administrativas, aumentos del presentismo sin consulta previa ${ }^{24}$, falta de aportes del gobierno a la obra social de los docentes (OSPLAD), conflictos que se recrudecieron en distintos momentos de 1986, hacia el final de la gobernación de Vernet. Como señalaría una docente entrevistada: "a Vernet le hicimos 9.999 movilizaciones" ${ }^{25}$, aspecto que a su vez develaron las actas del gremio: quite de colaboración con la no asistencia a actos oficiales, sentadas ante las regionales y el Ministerio de Educación, petitorios, reuniones de delegados, movilizaciones regionales, campañas de difusión, volanteadas, paros progresivos de una hora por día y por turno, paros con asistencia a los lugares de trabajo, reuniones de padres, eventos culturales, etcétera ${ }^{26}$.

Como se puede observar, durante este período el sindicalismo docente llevó adelante diferentes repertorios de acción que apuntaban a establecer una relación con la

\footnotetext{
23 Por ejemplo, a fines de marzo de 1985, se llevaron a cabo movilizaciones de docentes en todo el país ante la falta de política salarial por parte del gobierno nacional y por la jerarquización salarial de docentes de media, técnica, terciaria y universitaria, diario El Litoral, 26/03/1985, p. 4.

${ }^{24}$ Señalamos este punto en particular porque fue un tema que generó una fuerte resistencia en el gremio. La medida ministerial implicaba el aumento de 20 australes por presentismo, además de 20 australes para los docentes que se desempeñaban frente al aula. Esta decisión unilateral por parte del gobierno supuso para la AMSAFE una afrenta muy grande, porque minaba los reclamos que se le venían haciendo al Estado provincial desde hacía tiempo, cfr. Archivo de la Asociación del Magisterio de Santa Fe, Delegación Castellanos, Acta de Asamblea Provincial, 24/19/1986.

${ }^{25}$ Entrevista a Docente 2 [grabación], realizada por María Cecilia Tonon en Rafaela el 15/04/2013. Registro en formato MP3. Archivo personal de los autores de este trabajo.

${ }^{26}$ Cfr. Archivo de la Asociación del Magisterio de Santa Fe, Delegación Castellanos, Actas de Asambleas Provinciales, 03/03/1986 a 23/12/1986.
} 
comunidad educativa. Hubo una preocupación permanente por construir lazos de solidaridad con padres y distintos sectores de la sociedad a los fines de fortalecer la organización de las acciones colectivas que debían emprenderse para no quedar aislados. En este sentido, caben señalar medidas tales como: campañas de difusión que comprendían a Federación de Cooperadoras, medios de comunicación, otros gremios, partidos políticos, etc-; formación de "Comisiones de Apoyo", paros activos, con asambleas en las escuelas y con participación de alumnos; reuniones de padres para explicitar el problema docente, como así también una función social específica en el contexto de inundaciones que asolaron a diferentes partes de la provincia de Santa $\mathrm{Fe}$, con actividades solidarias en las escuelas inundadas.

Pero también existía un especial interés en contestar las consideraciones que, en contra del gremio, el gobierno sembraba en la opinión pública a través de los medios ${ }^{27}$, cuestión bastante habitual cuando se trata de servicios públicos y privados que debe asegurar el Estado -educación, salud, transporte-. En cierta medida, el conflicto se trasladó al espacio mediático y su éxito pareció depender del favor o disfavor de la opinión pública. Evidentemente, la utilización recurrente de los medios de comunicación se configuraba como un importante repertorio de acción (Tilly, 2000) que abría otro frente de lucha para el sector sindical.

\section{Radicalización de los conflictos: las huelgas de 1988 y 1989}

A comienzos de 1988, los sindicatos de AMSAFE y SADOP expresaron un malestar generalizado que respondió a demandas insatisfechas de orden local imbricadas con reivindicaciones que compartía la mayoría de los docentes de todo el país, que fueron acumulándose durante la década y que se nacionalizaron en marzo, a partir de la huelga por tiempo indeterminado que decidió el Congreso nacional de la CTERA ${ }^{28}$.

A nivel nacional, las discusiones entre los sindicatos y el gobierno se dieron en el marco de la denominada Comisión de Política Salarial Docente, en la que participaron funcionarios del gobierno nacional ${ }^{29}$, de los gobiernos provinciales ${ }^{30}$ y dirigentes sindicales docentes.

\footnotetext{
${ }^{27}$ En una de las tantas actas de las asambleas provinciales del año 1986 donde se plantea esta medida, se señala lo siguiente: "es necesario responder a la solicitada del Ministerio y declaraciones que agravian al docente y al gremio (...) Publicar una solicitada en los distintos diarios importantes de la Provincia, en respuesta a las declaraciones del Ministro de Educación...", Archivo de la Asociación del Magisterio de Santa Fe, Delegación Castellanos, Actas de Asambleas Provinciales, 4/04/1986, s/p.

${ }^{28}$ Las dificultades más acuciantes se vieron en el orden de salarios y prestaciones sociales de los docentes, como así también en el plano de algunos servicios educativos. Véase al respecto Andelique C. y Tonon M. C. (2014).

29 Durante el conflicto, las máximas autoridades del Ministerio de Educación y Justicia de la Nación fueron Jorge Sábato como ministro de Educación; Adolfo Stubrin como secretario de Educación; Héctor Gutiérrez como subsecretario de Relaciones Educativas, y Juan Carlos Pugliese (h) como subsecretario de Gestión Educativa, datos extraídos del diario El Litoral, 11/03/1988.

${ }^{30}$ Los ministros de Educación de cada una de las jurisdicciones participaron de las asambleas que se produjeron en el marco del Consejo Federal de Educación y Cultura. Durante el desarrollo del conflicto se
} 
La CTERA, como señalábamos anteriormente, venía de una fractura importante producida en 1987. Sin embargo, durante este conflicto actuó de manera coordinada. Ahora bien, ¿por qué actuaron de manera conjunta ambas CTERA? El reclamo principal que aglutinó las posiciones en todos los sindicatos fue la unificación salarial a nivel nacional planteada desde 1983. Efectivamente, uno de los principales problemas que denunciaban era respecto a las diferentes remuneraciones salariales que se cobraban en todo el país ya que, en términos comparativos, docentes que cumplían la misma función cobraban salarios distintos según dependieran de administraciones provinciales -con más o menos recursos- o de la administración nacional, generando entonces que se incumpliera uno de los derechos básicos establecidos en el artículo 14 Bis de la Constitución nacional: igual remuneración por igual tarea. Para ello, se tomó como criterio unificador el salario del cargo de maestro de grado con jornada simple. Empero, no dejaron de marcarse las diferencias. Por un lado, la CTERA liderada por Arizcuren planteaba la sanción de un Nomenclador Único Nacional sobre un sueldo básico de 1.000 australes para el cargo de maestro de grado de jornada simple, respetando las equivalencias entre los distintos cargos del escalafón y su correlación entre niveles y modalidades ${ }^{31}$; mientras que la CTERA liderada por Garcetti solicitaba 770 australes. La diferencia en el monto salarial reclamado generaba que la CTERA reconocida oficialmente por el gobierno como única interlocutora estuviera más cerca de aceptar cifras menores ${ }^{32} \mathrm{y}$, por lo tanto, más proclive a la negociación.

En la provincia de Santa Fe, el recientemente asumido gobernador, el peronista Víctor Félix Reviglio, comenzó su gestión proponiendo un "pacto social" con los diferentes sectores gremiales, a modo de compromiso de las distintas fuerzas para transitar las difíciles circunstancias por las que atravesaba la provincia. Según las declaraciones de Reviglio, aparecidas en el diario El Litoral en los días previos al inicio de la huelga docente, el gobierno parecía mantener muy buenas relaciones con el gremio más representativo de la docencia santafesina ${ }^{33}$.

Lo cierto es que, a pesar de las expresiones y medidas tomadas por el gobierno, ya desde mediados de febrero de 1988, la AMSAFE denunciaba "ambigüedades y contradicciones" por parte del Ejecutivo provincial respecto de este acuerdo ${ }^{34}$. Estas

realizaron varias asambleas extraordinarias procurando conformar un nomenclador único para todo el país, cuestión nada fácil si se tiene en cuenta la diversidad de cargos y nomenclaturas que existían a lo largo del país, cfr. UNESCO (1999).

${ }^{31}$ Cfr. CTERA, Documento de la Junta Ejecutiva, Buenos Aires, 24/02/1988.

32 El gobierno ofrecía 500 australes, lo cual evidencia la enorme distancia con la demanda del sector liderado por Arizcuren.

33 Diario El Litoral, 4/03/1988, p. 1.

${ }^{34}$ Se observa en las diferentes asambleas de principios de año una renuencia al pacto social y una actitud de desconfianza hacia la postura del gobierno provincial, que llevó a "rechazar en todos sus términos la propuesta de pacto social ofrecida por el gobierno" y "elaborar una contrapropuesta con la presencia y participación de las bases docentes; coordinar con los demás gremios estatales y CGT", cfr. Archivo de la 
relaciones fluidas entre el sindicalismo docente y el gobierno, producido a través de audiencias y reuniones, no alcanzó para solucionar un conflicto que articulaba problemas de carácter provincial con demandas de carácter nacional.

En el contexto del plan de lucha propuesto por las dos CTERA, los docentes nacionales y provinciales, de los ámbitos oficiales y privados afiliados a AMSAFE, UDA, FADUL, AEP y SADOP, no comenzaron las clases en marzo de 1988 en la provincia de Santa Fe, dando cuenta de la contundencia de la medida y de su amplitud.

El paro por tiempo indeterminado que se inició el 14 de marzo en todo el país -con excepción de Corrientes ${ }^{35}$ - tuvo diferentes modalidades de implementación. En la provincia de Santa $\mathrm{Fe}$, la convergencia de intereses de los diferentes sindicatos de alcance nacional y provincial llevó a la conformación de un Frente Gremial de Trabajadores de la Educación que por primera vez en la historia de las luchas sindicales docentes de la provincia se unieron en el reclamo y la acción, al que se sumaron organizaciones estudiantiles -Centros de Estudiantes Secundarios y la Federación Universitaria del Litoral- y padres. En diferentes momentos durante el desarrollo del conflicto, el ministro de Educación llamó al diálogo y concertó reuniones con los sindicatos más importantes que integraron el Frente Gremial de los Trabajadores de la Educación. De hecho, propició la constitución de una Comisión de Política Salarial con el objetivo de acordar en el ámbito de la provincia con los principales sindicatos. De alguna manera, buscó diferenciarse del gobierno nacional deslindando responsabilidades y mostrando públicamente la disposición del gobierno provincial para solucionar el conflicto. Mientras tanto, por el lado de la Nación, el ministro de Educación y Justicia, Jorge Sábato, señalaba que las provincias eran las responsables frente a la política salarial y que cualquier aumento debía concertarse con cada una de ellas. En medio de una maraña de declaraciones y acusaciones entre los gobiernos provinciales y el nacional, el conflicto continuó sin solución.

Una gran movilización denominada Marcha blanca se llevó a cabo el 25 de marzo. La manifestación docente adquirió un carácter fuertemente confrontativo con la política del Ministerio de Educación de la Nación, y ante el fracaso de las negociaciones en la Comisión de Política Salarial, el gobierno nacional decidió no hacer más propuestas a los docentes y dejar librado a los ámbitos provinciales los acuerdos salariales con los respectivos gremios del sector que actuaban en cada jurisdicción (Glaz, 2002: 25). Evidentemente se buscaba fracturar la unidad lograda por los docentes de todo el país, provincializando los conflictos y dejando en manos de cada gobierno provincial su solución. Sin embargo, las ofertas diferenciadas que intentaron implementar las

Asociación del Magisterio de Santa Fe, Delegación Castellanos, Acta de Asamblea General Extraordinaria, 19/02/1987 y ss.

${ }^{35}$ Cabe aclarar que el sindicato de los docentes correntinos no estaba alineado a ninguna confederación nacional. 
provincias y el gobierno nacional no lograron quebrar la huelga ${ }^{36}$, y fueron totalmente rechazadas por los sindicatos provinciales y nacionales.

Ante la fortaleza que mostraban los docentes, el gobierno nacional estableció la conciliación obligatoria a mediados de abril, lo que implicó retrotraer el conflicto al inicio de la huelga. Este nuevo escenario obligó a los sindicatos a deliberar y decidieron aceptar la conciliación obligatoria, reanudando las clases el 20 de abril. En este contexto, la CTERA liderada por Garcetti convocó a una marcha nacional desde los diferentes puntos del país para concentrarse finalmente en la ciudad de Buenos Aires. Ante la falta de resolución en los plazos previstos por la conciliación obligatoria, el ministerio de Trabajo decidió prorrogarla por cinco días más. En el documento que firmaron el gobierno y sindicatos intervinientes, la CTERA "delega[ba] en las entidades de base, hasta tanto dur[as]e la conciliación, la capacidad de discutir con cada jurisdicción el cumplimiento de los fines escolares previstos y el tratamiento de los días descontados por la huelga" (Glaz, 2002: 28). De esta manera, la central gremial que hasta unos días antes había intentado nacionalizar el conflicto, lo fragmentó, dejando que las entidades de base discutieran aisladamente con cada gobierno jurisdiccional, debilitando la capacidad de negociación. El resultado fue el previsible: una lucha desarticulada y de muerte anunciada.

A pesar de las divergencias y de la fragmentación, la denominada Marcha blanca atravesó las diferentes ciudades del país en el camino a la ciudad de Buenos Aires. Las columnas docentes partieron de las ciudades de Misiones, Mendoza, Tucumán y Neuquén, contando con un apoyo importante en las localidades de la provincia de Santa Fe que recorrió.

El conflicto terminó con el Congreso Extraordinario de la CTERA del 24 de mayo, en el cual se suspendió la huelga por tiempo indeterminado hasta el receso de invierno. Esta decisión impulsada por la conducción de Garcetti obedeció al acuerdo previo entre el gobierno y la CTERA $^{37}$, y a la aprobación de la ley ${ }^{38}$ que permitió obtener los recursos para asegurar los aumentos salariales. Por otra parte, se facultó a la conducción ejecutiva de la CTERA y a los gremios de base para negociar en cada jurisdicción los descuentos por los días de paro, avalando en los hechos la resolución atomizada del conflicto y aceptando tácitamente el fracaso del principal objetivo que se propuso la huelga, la unificación salarial, ya que continuaron las diferencias salariales entre las

\footnotetext{
${ }^{36}$ No obstante, en Capital Federal, los docentes afiliados a la Confederación de Maestros volvieron al trabajo, así como docentes de la provincia de Córdoba.

${ }^{37}$ Para que el acuerdo se realizara, mediaron el secretario general de la CGT, Saúl Ubaldini y el diputado democristiano Carlos Auyero, con el pretexto de lograr una "victoria sin derrotados" para ambas partes, diario El Litoral, 20/05/1988, p. 1.

${ }^{38}$ La ley fue aprobada por el Congreso el 19 de mayo y promulgada con el número 23.562, diario El Litoral, 20/05/1988, p. 1.
} 
distintas jurisdicciones ${ }^{39}$. De esta manera, el gobierno nacional había logrado su objetivo: regionalizar el conflicto. Es decir, de ahora en más, cada gobierno provincial debía solucionar las demandas salariales y laborales con los sindicatos de base que tuvieran mayor incidencia en sus respectivos territorios.

Esta provincialización de los conflictos docentes se hizo sentir en 1989, generando que las medidas de acción colectivas no gozaran a nivel nacional de la contundencia y extensión que tuvieron en 1988. En este sentido, la conducción de la CTERA liderada por Marcos Garcetti y Mary Sánchez se mostró proclive a negociar con el gobierno y a adoptar posturas dialoguistas en el marco de una paritaria nacional convocada por la gestión radical con participación de ministros provinciales. En el congreso que se realizó durante marzo decidieron impulsar la aceptación de la oferta salarial, abriendo el camino para un inicio de clases sin $\operatorname{conflictos}^{40}$, situación que contrastó con el no inicio de clases del año anterior.

Sin embargo, esta medida de la CTERA no fue la que los docentes afiliados a la AMSAFE terminaron aceptando. Cabe recordar que los delegados de la AMSAFE que participaron en el Congreso de la CTERA llevaron como mandato el paro por tiempo indeterminado. Esta opción no fue asumida por la mayoría de las jurisdicciones ${ }^{41}$. Todo lo contrario, al igual que el año anterior, la AMSAFE inició un paro por tiempo indeterminado, pero esta vez desacoplándose de la entidad nacional a la cual pertenecía, por un lado, porque seguía sus propias reivindicaciones vinculadas a los reclamos históricos provinciales referenciados anteriormente y, por otro lado, por las diferencias políticas que varias líneas internas de la AMSAFE mantenían con la conducción de la CTERA, a la que consideraban burocrática y antipluralista. Evidentemente, esta opción claramente opositora y disruptiva de la AMSAFE la condujo a una situación de total aislamiento ya que, además de la CTERA, la mayoría de las entidades gremiales que actuaban en la provincia (UDA, SADOP, AEP) aceptaron la oferta del gobierno y no fueron a la huelga.

En este marco, el gobierno provincial salió rápidamente ante la opinión pública a descalificar la actitud del gremio y a tomar medidas represivas contra los docentes: declarar ilegal la huelga y descontar los salarios por los días de paro ${ }^{42}$. Hasta se llegó a anunciar que se dejaría cesantes a interinos y reemplazantes que no se presentaran a trabajar.

\footnotetext{
39 A modo de ejemplo, se puede citar el caso de la provincia de Córdoba donde el salario mínimo acordado fue de 901 australes para mayo, mientras que a nivel nacional fue de 750 australes, diario $\mathrm{El}$ Litoral, 25/05/1988, p. 1.

${ }^{40}$ Diario El Litoral, 3/03/1989, p. 1.

${ }^{41}$ Diario El Litoral, 1/03/1989, p. 1

${ }^{42}$ Diario El Litoral, 9/03/1989, p. 3.
} 
El conflicto adquirió tal agravamiento en mayo, que padres ${ }^{43}$ y cooperadores participaron de varias reuniones y movilizaciones reclamando al gobierno una solución al problema que tuvo a las escuelas sumidas en paros que iban desde las 24 a las 72 horas por semana, repertorios de acción que ya se venían realizando de manera intermitente, pero continua, desde el inicio del ciclo lectivo 1989.

Finalmente, el enfrentamiento se resolvió unos días antes de que se produjeran los saqueos y el estallido social en el que derivó el proceso hiperinflacionario. Probablemente, la fuerte presión que ejercieron los docentes con sus planes de lucha, la movilización de padres y cooperadores, y el contexto de crisis económica fueran las variables más importantes para explicar la firma del acta acuerdo con los dirigentes gremiales, en la que el sindicato se comprometió a levantar los paros programados -ad referéndum de la asamblea- y el gobierno retrocedió en sus posturas represivas asumidas al inicio del conflicto, comprometiéndose a pagar los salarios descontados a los huelguistas. Para agosto de 1989, los docentes santafesinos agremiados en la AMSAFE retornaron a las aulas luego de haber concertado "dictar clases sin paros durante cien días", a cambio de que el gobierno provincial cumplimentase la medida de pagar los "sueldos íntegros antes del día 10 de cada mes" ${ }^{44}$. Se cancelaron así, por un breve tiempo, los conflictos entre la AMSAFE y las autoridades provinciales; los mismos se reavivarían más adelante, pero ya atravesados por definiciones nacionales de CTERA $^{45}$ y en el marco de los primeros meses de la presidencia de Carlos Menem, que excede las dimensiones analíticas propuestas para este trabajo.

\section{Consideraciones finales}

En este trabajo nos propusimos caracterizar la conflictividad docente entre 1983 y 1989 en la provincia de Santa Fe, a partir del análisis de las acciones colectivas emprendidas por el sindicato provincial de mayor incidencia en la docencia santafesina: AMSAFE. Para ello, procuramos dar cuenta del contexto educativo en el cual se movilizaron, de las razones que motivaron las huelgas que llevaron a cabo los trabajadores docentes santafesinos a través del sindicato, de las formas que adoptó la lucha, de las relaciones con los gobiernos democráticos de turno y de las articulaciones y disputas internas, tanto de la propia organización como de la CTERA en la cual se alineaba a nivel nacional.

Aunque la huelga se configuró en el principal repertorio de acción utilizado, también hemos podido identificar otras acciones importantes como campañas de difusión a través de los medios masivos de comunicación, la conformación de frentes gremiales

\footnotetext{
${ }^{43}$ Los padres conjuntamente con los cooperadores presentaron un recurso de amparo contra el gobierno, reclamando al Poder Ejecutivo una solución inmediata a la falta de continuidad del servicio educativo. Diario El Litoral, 24/05/1989.

${ }^{44}$ Diario La Opinión, 9/08/1989, p. 2.

${ }^{45}$ Diario La Opinión, ediciones octubre-diciembre de 1989.
} 
con otros sindicatos docentes, la relación con organizaciones civiles y políticas para lograr apoyo, la realización de eventos masivos -festivales, por ejemplo-, la formación de comisiones, la realización de asambleas masivas y reuniones de esclarecimiento con padres y alumnos.

El análisis nos ha permitido reconocer ciertas diferencias en el desarrollo de los acontecimientos, lo que posibilita establecer ciertas cesuras temporales que marcarían períodos con características particulares que le otorgan cierta especificidad. En este sentido, se puede señalar que en los primeros años de la década de los ochenta, en las relaciones entre los gobiernos -nacional y provincial- y los sindicatos docentes, primó la negociación. Probablemente, la expectativa depositada en el retorno a la democracia después de tantos años de silencio y represión explique la permanente búsqueda de acuerdos a través del diálogo.

En cambio, en la segunda mitad de la década, los conflictos se multiplicaron y los docentes santafesinos fueron parte de un ciclo de huelgas y protestas que se agudizó entre 1988 y 1989. Pero cómo se explica este cambio de actitud. Sin dudas, las causas son múltiples. Por un lado, la inflación progresiva fue quizás uno de los factores fundamentales que afectó en general los ingresos salariales de la mayoría de los trabajadores, y de los docentes en particular; situación que se puede observar en la creciente demanda de aumentos salariales. Por otro lado, la paulatina deslegitimación política de estos primeros gobiernos democráticos que no resolvieron los problemas que en las campañas electorales habían prometido. Finalmente, cabe señalar la falta de respuesta a demandas específicas que los docentes venían reclamando a las autoridades provinciales y nacionales desde hacía varios años, como la unificación salarial, la reforma educativa, atrasos en la efectivización de los salarios, deudas pendientes con interinos y reemplazantes, omisiones administrativas, aumentos del presentismo sin consulta previa, falta de aportes del gobierno a la obra social de los docentes (OSPLAD), entre otros. En definitiva, en la creciente conflictividad docente que se desarrolló entre 1986 y 1989 se imbricaron causas socioeconómicas y educativas, tanto de carácter nacional como provincial.

La huelga por tiempo indeterminado de 1988 que aglutinó a todos los docentes del país se constituyó en una experiencia inédita para el colectivo docente. En la provincia de Santa Fe resultó fuertemente significativa, ya que los repertorios de acción fueron implementados a partir de un Frente Gremial de Trabajadores de la Educación que agrupó a la mayoría de los sindicatos docentes con actividad gremial en la provincia. Consideramos que esta situación permitió a los docentes santafesinos fortalecer el plan de lucha ante el gobierno provincial, y generar espacios masivos de participación y acción colectiva que reunieron a docentes, estudiantes, padres, asociaciones cooperadoras, civiles y culturales en un mismo reclamo.

Ahora bien, en general, los gobiernos nacionales y provinciales establecieron relaciones con los sindicatos que fluctuaron entre el diálogo y la confrontación. En este 
sentido, se pueden identificar dos estrategias: por un lado, durante la huelga de 1988, tanto el gobierno nacional como los gobiernos provinciales plantearon la provincialización del conflicto para fragmentar la unidad nacional de los trabajadores docentes con la colaboración de algunos dirigentes de la CTERA, especialmente de aquellos alineados al peronismo. Por otro lado, cuando el conflicto no pudo canalizarse por vías institucionales, recurrieron a la utilización de medidas intimidatorias y coercitivas para disuadirlos de realizar la huelga. Esta última estrategia gubernamental se puede observar claramente en el largo conflicto que enfrentó a la AMSAFE con el gobierno provincial de Santa Fe en 1989.

Desde el lado de los sindicatos docentes es posible reconocer diferentes repertorios de acción para enfrentar al gobierno, tanto nacional como provincial. En términos generales, se pueden identificar acciones más conciliadoras y dialoguistas, como las de la Lista Celeste liderada por Garcetti, y que entraban en tensión con otras medidas más intransigentes, como aquellas planteadas por la CTERA liderada por Arizcuren en las huelgas nacionales de 1988, o las que llevó adelante la AMSAFE en el conflicto provincial que se desarrolló de manera aislada en 1989.

Para finalizar, nos parece importante señalar que este artículo ha pretendido ser una aproximación inicial a un período de la lucha sindical docente de la provincia de Santa $\mathrm{Fe}$, de cuya profundización podrán desplegarse nuevos interrogantes, líneas de análisis e hipótesis explicativas que permitan problematizarlo.

\section{Referencias bibliográficas}

Alonso, L. (2006). Estabilidad constitucional, desarrollo asimétrico y procesos de regionalización, 1983-2003. En Águila, G. (ed.) De los cordones industriales a la integración del eje Mercosur: 1940-2005. Rosario: Prohistoria, pp. 109-156.

Andelique, C. M. (2012). El incremento de la conflictividad docente en Santa Fe, c. 19661971. Ponencia presentada en la VI Jornada sobre Historia Reciente, Santa Fe.

Andelique, C. M. y Tonon, M. C. (2014). Las transformaciones organizacionales de los sindicatos regionales argentinos en la segunda mitad del siglo XX. El caso de la Asociación del Magisterio de Santa Fe (1966-1989). Ponencia presentada en Nuevos Talleres Internacionales de Estudios Regionales y Locales (urbanos) IV "La región: pasado y actualidad", Santa Clara, Cuba.

Andelique, C. M. y Tonon, M. C. (2014). La conflictividad docente en la década del ochenta en Argentina: el caso de los docentes santafesinos y la huelga de 1988. En Naveg@mérica. Revista electrónica editada por la Asociación Española de Americanistas, $\mathrm{N}^{\circ} 12$.

Andelique, C. M. y Tonon, M. C. (2016). Organizaciones gremiales y estrategias de acción de los trabajadores docentes en Santa Fe durante el tercer peronismo 
(1973-1976). Ponencia presentada en la VIII Jornada sobre Historia Reciente, Rosario.

Braslavsky, C. (1989). La educación en la transición a la democracia: elementos y primeros resultados de una comparación. Revista Propuesta Educativa, Vol. 1, N 1, pp. 30- 43.

Braslavsky, C. (1995). Acerca de la reconversión del sistema educativo argentino (19841995). Documentos e Informes de Investigación, № 190. Buenos Aires: FLACSO.

Cavarozzi, M. (2006). Autoritarismo y democracia (1955-2006). Buenos Aires: Ariel.

Diana Menéndez, N. (2005). ATE y UPCN: dos concepciones en pugna sobre la representación sindical de los trabajadores estatales. En Fernández, A. (comp.) Estado y relaciones laborales: transformaciones y perspectivas. Buenos Aires: Prometeo Libros, pp. 169-191.

Fernández, A. (2005). Las transformaciones del Estado y de su política laboral: un enfoque teórico. En Fernández, A. (comp.) Estado y relaciones laborales: transformaciones y perspectivas. Buenos Aires: Prometeo Libros, pp. 11-44.

Glaz, E. (2013). La huelga blanca. Tesis de Licenciatura. Universidad Nacional de La Plata, Facultad de Humanidades y Ciencias de la Educación. Buenos Aires.

Migliavacca, A. (2006). La huelga docente de 1988. Una aproximación desde la perspectiva de los docentes autoconvocados. Trabajo presentado al VI Seminario da Redestrado. Río de Janeiro, Brasil: UERJ, pp 1-15.

Novaro, M. y Palermo, V. (2006). La dictadura militar 1976/1983. Del golpe de Estado a la restauración democrática. Buenos Aires: Paidós.

Novaro, M. (2009). Argentina en el fin de siglo. Democracia, mercado y nación (19832001). Buenos Aires: Paidós.

Orlansky, D. (1996). Reforma del Estado, reestructuración laboral y reconversión sindical en el sector público. Revista Aportes para el estado y la administración gubernamental, $N^{\circ}$ 6, Buenos Aires.

Ortiz, R. y Schorr, M. (2006). La economía política del gobierno de Alfonsín: creciente subordinación al poder económico durante la década perdida. En Pucciarelli, A. (coord.) Los años de Alfonsín ¿El poder de la democracia o la democracia del poder? Buenos Aires: Siglo Veintiuno Editores, pp. 291-333.

Pozzi, Pablo (1988). Oposición obrera a la dictadura (1979-1983). Buenos Aires: Editorial Contrapunto.

Schneider, A. (2000). 'Ladran Sancho...'. Dictadura y clase obrera en la zona norte del Gran Buenos Aires. En Camarero, H.; Pozzi, P. y Schenider, A. (eds.) De la revolución libertadora al menemismo. Historia social y política argentina. Buenos Aires: Imago Mundi.

Tilly, Ch. (2000). Acción colectiva. Apuntes de investigación, N 6, Buenos Aires.

Torre, J. C. (1998). El proceso político de las reformas en América latina. Buenos Aires: Paidós. 


\section{Fuentes mencionadas en el trabajo}

Unesco (1999). Balance de los últimos 20 años de educación en la Argentina y prospectiva hacia el siglo XXI. Buenos Aires: UNESCO.

-Archivo de la Asociación del Magisterio de Santa Fe, Delegación Castellanos, Actas de Asambleas Provinciales, febrero de 1984-diciembre de 1989, mimeo.

-Archivo de la Asociación del Magisterio de Santa Fe, Delegación Castellanos, Actas de Asambleas Generales Extraordinarias, febrero de 1987-junio de 1988, mimeo.

-Archivo del Diario El Litoral, Santa Fe, 1983 a 1989.

-Archivo del Diario La Opinión, Rafaela, 1989.

-Argentina. Ministerio de Educación. Ley N²3114. Buenos Aires, Argentina, 30 de septiembre de 1984 Recuperado de

http://www.fmmeducacion.com.ar/Sisteduc/Segundocongreso/ley23114.

\section{Entrevistas}

-Entrevista a Docente 1 [grabación], realizada por María Cecilia Tonon en Rafaela el 21/03/2013. Registro en formato MP3. Archivo personal de los autores de este trabajo. -Entrevista a Docente 2 [grabación], realizada por María Cecilia Tonon en Rafaela el 15/04/2013. Registro en formato MP3. Archivo personal de los autores de este trabajo. 